\title{
How social media is changing cardiology
}

\section{(DElnur Smajić1*, (C) Nihad Mešanović', -Edin Begić ${ }^{2}$}

'University Clinical Center Tuzla, Tuzla, Bosnia and Herzegovina

${ }^{2}$ General Hospital "Prim. dr. Abdulah Nakaš", Sarajevo, Bosnia and Herzegovina

\section{RECEIVED:}

October 26, 2018

ACCEPTED:

November 5, 2018

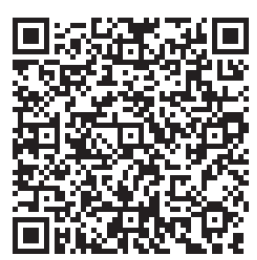

$\square$ Cardiologia Croatica 2018:13(11-12):462.
KEYWORDS: cardiology, social media, hashtag.

CITATION: Cardiol Croat. 2018;13(11-12):462. | https://doi.org/10.15836/ccar2018.462

*ADDRESS FOR CORRESPONDENCE: Elnur Smajić, JZU Univerzitetski klinički centar Tuzla, Trnovac bb, 75000 Tuzla, Bosnia and Herzegovina. / Phone: +387-61-185-437 / E-mail: elnur.smajic@ukctuzla.ba

ORCID: Elnur Smajić, https://orcid.org/0000-0003-0881-9443 • Nihad Mešanović, https://orcid.org/0000-0003-1912-1155 Edin Begić, https://orcid.org/0000-0001-6842-262X

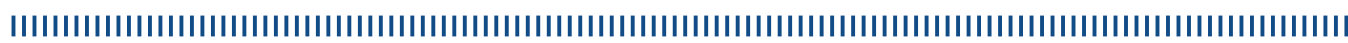

Human beings are social creatures, and in fact need social interactions to maintain a healthy life and mind. The earliest methods of communicating across great distances used written correspondence delivered by hand from one person to another are letters. The earliest form of postal service dates back to 550 B.C. The environmental and genetic factors contribute to social media use. One- to two- thirds of variance in social media use is attributable to additive genetic traits; unique and shared environmental factors account for the remainder of variance..$^{1-5}$

After the first super computers were created in the 1940s, scientists and engineers began to develop ways to create networks between those computers. The earliest forms of the Internet, such as CompuServe, were developed in the 1960s. From the first recognizable social media site, Six Degrees, via LinkedIn, YouTube to Facebook and Twitter became available to users throughout the world. LinkedIn represent a professional platform. Twitter is a micro blogging site and is one of the most commonly used forms for this medium. The technology is rapidly evolving and the sharing of medical scientific information is moving from print and on-site presentations to digital online publication (webinars, etc.). Social media is the ideal platform for this development, and cardiology is a leader in this form of communication.

The patients are very active on social media, and the numbers of electronic patients continues to grow. The internet use is not limited to the millennial generation, more than two-thirds of all seniors go online every single day and more than half of these seniors go online in order to access health information. Users who Tweeted about cardiovascular disease were more likely to be older than the general population of Twitter users and less likely to be male. A growing percentage of patients use social media for health-related reasons. These effects will contribute to a better understanding of potential benefits and challenges for both patients and healthcare professionals, but also other healthcare actors.

Healthcare providers, medical institutions, medical societies, scientific journals and clinicians are recognized great potential for use of social media to improve health outcomes. The use of social media by cardiologists has increased substantially in recent years. While personal use is more common, approximately two-thirds of cardiologists interact with various social media platforms. For example, some cardiologists use social media to promote positive health behaviors, debate health care policy, network with colleagues, and to educate their patients, peers, and students. Specific Twitter cardiovascular journal clubs (\#Heart_BMJ, \#HeartJC), societies (\#escardio, \#ESCCongress), and hospitals (\#MayoClinicMinute) have become well established.

It is important to understand how to use social media in cardiovascular care: engaging directly with patients about a particular disease process, treatment options, and cardiovascular care, it should be provided generally and not specific to a particular patient; provide timely and credible information and disease-specific education to patients as well as colleagues; share medical information and disease-specific knowledge with colleagues around the world, develop a network to engage with colleagues and discuss best practices; market- share your expertise and abilities with the world, establish a national/international reputation and influence policy and practice guidelines.

Uses of social media in interventional cardiology, heart failure and cardiac rehabilitation improved patient outcomes and reduced financial burden of CVD on health systems. Social media have positive impact in both the primary and secondary prevention of cardiovascular diseases.

Social media opens the opportunity for fast- sharing of information, but no ideal process has been defined. This is leading to an increased number of posts, which unintentionally expose personal data, and once shared it can spread around the globe in seconds. We should protect data from "third parties" (\#ProtectMyData). There are some points that we have to keep in mind when using social media: best practice, strive accuracy, never identify a patient, ask permission, assume beneficence, be respectful.

The future of cardiovascular care will be transformed by advances in artificial intelligence, digital health technology and mobile devices as a means to prevent and treat heart disease. Cardiologists don't have to wait until major meetings to discuss new ideas, and now we have entire world. Social media is where we need to be.

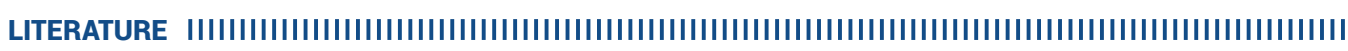

1. York C. A regression approach to testing genetic influence on communication behavior: Social media use as an example. Computers in Human Behavior. 2017;73;100-9. https://doi.org/10.1016/j.chb.2017.03.029

2. Small Business TRENDS [Internet]. Hendricks D. Complete History of Social Media: Then And Now; [cited 2018 0ct 210]. Avalable from: https://smallbiztrends.com/2013/05/the-complete-history-of-social-media-infographic.html

3. Patient Research Exchange [Internet]. Meier P. Social media and the future of medicine; [cited 2018 0ct 210]. Available from: https://www.patientresearchexchange.org/stories/detail/social-media-and-the-future-of-medicine

4. Campbell KR. The Use of Social Media In Cardiovascular Medicine. US Cardiology Review. 2016;10(1):41-2. https://doi.org/10.15420/usc.2016.10.1.41

5. Sinnenberg L, DiSilvestro CL, Mancheno C, Dailey K, Tufts C, Buttenheim AM, et al. Twitter as a Potential Data Source for Cardiovascular Disease Research. JAMA Cardiol. 2016 Dec 1;1(9):1032-1036. https://doi.org/10.1001/jamacardio.2016.3029 